\title{
Extrativismo do cambuí (Myrciaria sp.): conhecimentos, práticas e renda na comunidade Ribuleirinha, litoral sul de Sergipe
}

\author{
Extractivism of cambuí (Myrciaria sp.): knowledge, practice and income in Ribuleirinha \\ community, south coast of Sergipe
}

\author{
Liziane Rodrigues dos Santos ${ }^{1}$ \\ Laura Jane Gomes ${ }^{2}$ \\ Carina Angelica dos Santos ${ }^{3}$ \\ Débora Moreira de Oliveira ${ }^{4}$
}

\begin{abstract}
Resumo
O cambuí (Myrciaria sp.), fruto do cambuizeiro, é um Produto Florestal Não Madeireiro (PFNM) considerado um componente da biodiversidade no estado de Sergipe, acrescido de valor econômico. O presente estudo teve como objetivo analisar os conhecimentos e práticas associados ao extrativismo do cambuí, bem como a renda gerada com a venda dos frutos na comunidade Ribuleirinha, localizada na zona litorânea do município de Estância, sul do estado de Sergipe. A pesquisa ocorreu entre novembro de 2017 e janeiro de 2018, por meio de entrevistas semiestruturadas, em que foram utilizadas ferramentas do Diagnóstico Rural Participativo, e os participantes foram selecionados por meio da técnica "Bola de Neve". Constatou-se que o extrativismo da espécie é realizado predominantemente por mulheres, porém familiares contribuem nos picos de produção. Além do consumo doméstico, outras formas de aproveitamento, dentro e fora da comunidade, estão surgindo e agregando valor ao produto. Concluiu-se que o sistema extrativista é realizado por meio de práticas e uso de tecnologias simples, baseadas no conhecimento local. A venda dos frutos aparenta estar atrelada a uma demanda que tem aumentado nos últimos anos, contudo é considerada como um complemento para a renda familiar.
\end{abstract}

Palavras-chave: Produto Florestal Não Madeireiro. Sociobiodiversidade. Conhecimento local.

\begin{abstract}
Cambuí (Myrciaria sp.) is a fruit of the cambuizeiro tree and a Non-timber Forest Product (NTFP). It is considered a component of the biodiversity in Sergipe state with economic value. This research aimed to analyze the knowledge and practices that are associated with the cambuí extraction, as well as the income from the sale of the fruits in Ribuleirinha community which location is the coastal area of Estância municipality, in the south of Sergipe state. The research took place between November 2017 and January 2018, with semi-structured interviews and some means of Participatory Rural Appraisal, and the "Snowball" technique conducted the selection of the participants. It noticed that women perform the species extraction predominantly, but family members contribute during the

${ }^{1}$ Graduanda em Engenharia Florestal pela Universidade Federal de Sergipe (UFS). E-mail: lizyfloresta19@ gmail.com

2 Professora da UFS. Doutora em Engenharia Agrícola pela Universidade Estadual de Campinas. E-mail: laurabuturi@gmail.com

${ }^{3}$ Doutoranda em Desenvolvimento e Meio Ambiente (UFS). E-mail: profcarina@yahoo.com.br

${ }^{4}$ Doutora em Desenvolvimento e Meio Ambiente (UFS). E-mail: d.oliveira.doc@ gmail.com
\end{abstract}


production peaks. In addition to domestic consumption, other kinds of exploitation, both within and outside the community, are arising and adding value to the product. The research concluded that the extractive system accomplishment has simple practices and technologies, based on local knowledge. The sale of the fruit appears to be linked to a demand that has increased in recent years; however, it is considered as a supplement to the household income.

Keywords: Non-timber Forest Product. Sociobiodiversity. Local knowledge.

\section{Introdução}

Devido a suas condições climáticas e localização, o Brasil possui significativa diversidade de fauna e flora, sendo considerado um dos países mais ricos em biodiversidade do planeta (CORADIN; CAMILLO, 2016). No país, é comum a demanda de mercado por espécies vegetais exploradas por meio do extrativismo, inclusive daquelas conhecidas como Produtos Florestais Não Madeireiros (PFNM).

Os PFNM são definidos como os componentes vegetais que não se enquadram nos elementos madeira e lenha, oriundos de formações da vegetação naturais ou manejadas. Através destes produtos, várias comunidades rurais ou periferias urbanas tiram seu sustento e/ou complementam suas rendas. São exemplos de PFNM: castanhas, amêndoas, nozes, frutas, ervas, temperos, corantes, óleos, resinas, exsudados, fibras, cascas, plantas aromáticas, medicinais e ornamentais (SOLDATI, 2009).

Os recursos vegetais explorados por meio do extrativismo podem ser utilizados para diversos fins por uma determinada comunidade local e/ou tradicional, seja para subsistência ou para suprir demandas de mercado (GOMES; GOMES, 2000). Estudos sobre o extrativismo vegetal podem desempenhar um papel fundamental no entendimento da relação homem-planta, bem como na valorização da diversidade biológica e do conhecimento tradicional/local.

No estado de Sergipe, os principais exemplos de PFNM, com valor comercial, já estudados, são a pimenta-rosa, conhecida como aroeira-da-praia (Schinus terebenthifolius Raddi) (GOMES et al., 2013), e a mangaba (Hancornia speciosa Gomes) (OLIVEIRA et al., 2017a). Entre outros frutos coletados por meio do extrativismo, tem-se o cambuí (Myrciaria sp.) que, comparativamente, é um PFNM pouco estudado no estado de Sergipe.

O cambuizeiro é uma espécie nativa do Brasil que pertence à família Myrtaceae. Proença et al. (2013) encontraram registros da ocorrência de 4 espécies no estado de Sergipe: cambucá (Myrciaria aff. guaquiea); cambuí (Myrcia polyantha); cambuí (Myrciaria ferruginea); cambuí ou 
cambuí-do-mato (Myrciaria floribunda). Elas podem ser encontradas nos biomas mata atlântica, caatinga, cerrado e restinga (MORAIS et al., 2014).

Oliveira et al. (2017b) constataram que, nos municípios de Pirambu, Itaporanga D’Ajuda, Estância, Indiaroba e Japaratuba, as mulheres catadoras de mangaba também se dedicam à coleta do cambuí, inclusive no povoado Ribuleirinha, comunidade em que foi realizado este estudo.

A presente pesquisa partiu do princípio de que o extrativismo do cambuí, na comunidade ribuleirinha, é realizado a partir do conhecimento local, por meio de práticas e uso de tecnologias simples. Desta forma, procurou-se responder os seguintes questionamentos: Quais são os conhecimentos e práticas locais relacionados ao extrativismo do cambuí? Qual a renda familiar gerada pelo extrativismo desta espécie?

\section{Procedimento metodológico}

\section{Área de estudo}

O Munícipio de Estância está situado na região sudeste do estado de Sergipe, com uma área de 644, 487 km² e com uma população de 68,846 mil habitantes (IBGE, 2016a). A distância entre o município e a capital do estado, Aracaju, através da BR-101, é de 68 km (SANTOS, 2011).

Devido à influência geográfica tropical, a baixa altitude e a posição litorânea, as temperaturas médias anuais variam entre $23,2^{\circ} \mathrm{C}$ e $26,5^{\circ} \mathrm{C}$. As precipitações variam de $1.300 \mathrm{~mm}$ a $1.800 \mathrm{~mm}$, sendo que no litoral do município as chuvas são mais acentuadas. A vegetação do município de Estância é caracterizada pelos remanescentes de cobertura vegetal de mata atlântica, cerrado arbustivo, na unidade morfológica dos tabuleiros costeiros e manchas de restinga e manguezais, na planície costeira (SANTOS, 2011).

A área escolhida para a pesquisa foi o povoado Ribuleirinha, que está situado mais precisamente na porção litorânea do município, entre as coordenadas: $11^{\circ} 21^{\prime} 51.49^{\prime \prime}$ e e 37¹9'26.36”. Convém destacar que, na área estudada, está situada a Associação das Catadoras de Mangaba do Povoado Ribuleirinha do Município de Estância (ASCAMARE), que possui uma linha de comercialização de geleias, trufas, licores, bolos e bombons feitos a partir de frutos da restinga sergipana, incluindo o cambuí.

\section{Coleta e análise das informações}


Para a coleta das informações, foi utilizado um roteiro de entrevista semiestruturada (SILVA et al., 2014) e o calendário sazonal de atividades geradoras de renda, que é uma ferramenta do Diagnóstico Rural Participativo (DRP). De acordo com Cerqueira (2015), o DRP é um dos métodos de investigação da realidade com ênfase a conhecer, levantar informações, avaliar uma realidade determinada, interpretar. Este tipo de instrumento proporciona o envolvimento da comunidade na construção e identificação de sua própria realidade (MENEZES et al., 2011).

Com a finalidade de responder às questões da pesquisa, o roteiro de entrevista abordou seis contextos dos indivíduos que praticam o extrativismo na região do estudo: perfil socioeconômico; histórico; percepção; processo de coleta, comercialização e renda.

Convém ressaltar que, para estudos relacionados ao extrativismo, dificilmente se tem conhecimento do número total de indivíduos que se dedicam à atividade - caso desta pesquisa. Este fator gerou a dificuldade em utilizar amostragem probabilística, conforme discutido por Silva et al. (2014). Segundo Alencar (1999), amostragem não probabilística por conveniência é aquela em que se escolhem os indivíduos mais acessíveis e dispostos a fornecer informações. Assim, a entrevista é realizada com um número não definido de pessoas e só poderá ser finalizada quando se constata que não há novas informações a serem acrescentadas.

Para isso, utiliza-se em conjunto com a amostragem não probabilística o método "Bola de Neve" (ALBUQUERQUE; HANAZAKI, 2010). De acordo com Vinuto (2014), esse tipo de abordagem é aquela na qual os informantes-chaves, denominados como sementes, indicam outros indivíduos em potencial, ou seja, com o perfil necessário para a pesquisa dentro da população de estudo. As pessoas que foram indicadas apontam novos indivíduos e, assim, este processo segue de forma sucessiva, até que o objetivo seja alcançado.

As entrevistas foram realizadas entre os meses de novembro de 2017 e janeiro de 2018, de acordo com a disponibilidade de tempo de cada indivíduo e somente com pessoas que praticam o extrativismo dos frutos de cambuí. O primeiro indivíduo a ser entrevistado foi identificado a partir da conversação com moradores locais e também pelo fato de o pesquisador obter conhecimento prévio sobre moradores envolvidos com o extrativismo do cambuí. Deste modo, o primeiro indivíduo foi tido como o informante-chave, pois indicou posteriormente outros indivíduos em potencial para a pesquisa que também contribuíram com novas indicações.

Durante o período de realização das entrevistas, após a apresentação do pesquisador, cada participante foi informado sobre a pesquisa e o seu objetivo. Somente após a concordância deles, o estudo foi realizado. Todos os entrevistados assinaram o Termo de Consentimento Livre Esclarecido 
para anuência de participação nesta pesquisa, que foi aprovada pelo Comitê de Ética e Pesquisa da Universidade Federal de Sergipe, por meio da submissão à Plataforma Brasil.

Para a análise dos dados, as respostas fechadas foram sistematizadas na ferramenta estatística IBM SPSS 20, o que possibilitou analisar os resultados expostos em porcentagens. As respostas abertas (falas dos entrevistados), quando consideradas pertinentes para o estudo, foram transcritas com a finalidade de apresentar de forma coerente os relatos dos entrevistados. Para preservar a identidade dos entrevistados, os nomes foram substituídos por "Entrevista X (número da entrevista), Y (idade)".

\section{Resultados e discussão}

\section{Perfil socioeconômico dos entrevistados}

$\mathrm{Na}$ comunidade, foram realizadas 21 entrevistas com pessoas que realizam a coleta do cambuí, seja para fins comerciais ou consumo próprio. Destas, sete (33\%) são integrantes da Associação das Catadoras de Mangaba no Povoado Ribuleirinha (ASCAMARE). Todas as entrevistadas são do sexo feminino, o que permite constatar que as mulheres são mais atuantes no que se refere ao extrativismo da espécie.

No estudo realizado por Gama et al. (2017), sobre o extrativismo do cambuí em Ribeira do Pombal-BA, constatou-se que as mulheres são mais participativas (60\%). Vários estudos demonstraram que as mulheres nordestinas têm participação predominante no extrativismo de outros PFNM, tais como o licuri (Syagrus coronata (Mart.) Beccari), na Bahia (SILVA, 2010), o coco do babaçu (Attalea speciosa), no Maranhão (FIGUEIREDO, 2005), e a mangaba (Hancornia speciosa Gomes), no Pará e em Sergipe (LIMA, 2012; MOTA et al., 2008).

A idade das entrevistadas variou entre 23 e 65 anos, sendo que: 57\% possui ensino fundamental incompleto; 4,8\% ensino fundamental completo; 33,4\% ensino médio completo; 4,8\% ensino superior completo. Segundo Silva et al. (2016), a baixa escolaridade em áreas rurais é justificada pela necessidade de obtenção imediata de renda e pelo fato de que as pessoas, ainda jovens, auxiliam nas despesas domésticas, ou não encontram oportunidade melhor de trabalho.

O número de filhos variou de 1 a 6 por família, sendo que $42,8 \%$ das entrevistadas possuem filhos maiores de 18 anos e 42,8\% possuem tanto filhos maiores quanto menores de idade. Apenas 
14,4\% não possuem filhos. Oitenta e um por cento (81\%) das participantes são naturais do município de Estância e, destas, 76,2\% residem no povoado Ribuleirinha desde que nasceram.

As mulheres que nasceram no povoado Ribuleirinha afirmam que coletam o cambuí desde criança, enquanto aquelas que vieram de outras localidades começaram a coletar entre 5 e 10 anos atrás - destas, apenas uma entrevistada não coleta cambuí nas áreas do povoado Ribuleirinha, pois tem costume de coletar no povoado onde nasceu, Caueira/Praia da Caueira, localizado no município de Itaporanga D'Ajuda-SE.

Em relação à profissão das entrevistadas, as duas profissões em que as mulheres mais se reconhecem são a de pescadora $(38,1 \%)$ e a de extrativista de mangaba e de cambuí $(14,3 \%)$. As mulheres se identificam como "pescadoras" e não como "marisqueiras", porque são registradas dessa forma para receber o seguro defeso. Além da profissão que se auto reconhecem, foram citadas outras atividades, entre elas estão: vendedora, cozinheira, diarista e marisqueira.

$\mathrm{O}$ fato de as profissões estarem voltadas ao extrativismo e à pesca ocorre em decorrência de a região ter influência costeira, presença de manguezais e, ainda, vegetação remanescente de restinga, utilizada para o extrativismo do estoque pesqueiro e vegetal, servindo como fonte de subsistência e renda para muitas famílias.

\section{Histórico e percepções sobre a atividade extrativista}

Segundo as entrevistadas que nasceram no povoado $(72,6 \%)$, a coleta do cambuí é realizada na localidade há mais de 50 anos. Quando questionadas sobre o que mudou na coleta do cambuí até os dias atuais, elas levantaram basicamente dois aspectos: quantidade coletada e aumento da importância, por meio da valorização do fruto e consequentemente seu melhor aproveitamento.

Para as entrevistadas que não nasceram no povoado, não houve mudanças na coleta do cambuí. Neste sentido, pode-se afirmar que o tempo de residência pode influenciar principalmente no nível de percepção na relação do indivíduo com o ambiente (TUAN, 2012).

A devastação das áreas de coleta, em virtude do desmatamento, queimadas e construção civil, foi o principal fator apontado por $38,1 \%$ das entrevistadas para a consequente queda na disponibilidade dos frutos.

Pelo fato de o cambuí estar localizado na mesma área de ocorrência da mangaba, pode-se estender a constatação do estudo realizado por Rodrigues et al. (2017). Nele, identificou-se que, entre os anos 2010 e 2016, houve uma redução de aproximadamente 30\% das áreas de ocorrência natural da mangaba no estado. Os mesmos autores citam que os fatores que contribuíram para a redução das 
áreas de mangabeiras, no estado de Sergipe, foram: a supressão da vegetação nativa para o plantio de cana-de-açúcar e eucalipto; a construção civil por meio da ampliação de áreas de condomínios fechados.

A redução das áreas de coleta poderá influenciar no deslocamento dos extrativistas para áreas mais distantes do povoado ou poderá acarretar o desinteresse da prática dessa atividade, visto que as entrevistadas afirmaram que preferem coletar o cambuí em locais próximos de onde residem.

Estudo realizado por Gama et al. (2017) apontou que a redução da produção dos cambuizeiros foi um fator que promoveu o desinteresse pelo extrativismo da espécie por parte dos atores envolvidos.

A intensificação dos períodos das "secas", isto é, redução da precipitação, foi um outro fator citado pelas extrativistas para justificar a queda na produção:

Antigamente, coletava mais, hoje é menos, por causa da destruição do ambiente e seca. (Entrevista 01, 47 anos)

O fenômeno da seca pode influenciar na fenologia da espécie, podendo modificar a época de floração, frutificação e capacidade produtiva. Outros PFNM possuem essa mesma problematização, como é o caso do pequi (Caryocar brasiliense Camb.), no Ceará, em que a falta de chuva e as queimadas interferem na produção, pois a falta de chuva provoca alternância na safra, não possuindo uma sazonalidade (PEREIRA et. al., 2014; OLIVEIRA; SCARIOT, 2010).

Apesar da redução da quantidade de frutos, em decorrência das áreas devastadas e secas, 28,6\% das entrevistadas afirmaram que o cambuí está mais conhecido, atualmente, em comparação ao passado, e que, por isso, hoje, obtém-se um maior aproveitamento. Para as extrativistas, isto pode estar contribuindo para o aumento da comercialização e consequente geração de renda para as pessoas da comunidade.

Hoje, é melhor, gera mais renda. Antes, era mais desconhecido. (Entrevista 17, 50 anos)

Mudou muita coisa. Eu só panhava pra fazer suco e chupar. Agora, eu ganho dinheiro, já faz um sorvete, um licor, biscoito... (Entrevista 03, 53 anos)

Antes, botava e o pessoal não panhava. Naquele tempo, não vendia era só pra chupar. Hoje, vende mais, tem algum desenvolvimento. (Entrevista 05, 41 anos)

O cambuí ficou mais conhecido e isso auxiliou no processo de aproveitamento, ou seja, houve melhores e múltiplas maneiras de utilizá-lo. Mesmo entre as extrativistas entrevistadas que não 
são associadas $(66,7 \%$ - não produzem e vendem os coprodutos do cambuí na ASCAMARE - existe a prática de beneficiamento do fruto, seja para polpas, sucos, licores, mousses ou sorvetes para o consumo próprio.

O fato da espécie ficar mais conhecida e mais valorizada pode ser considerado como um aspecto positivo, no âmbito econômico e social, pois as extrativistas podem aumentar a renda e serem reconhecidas pelas suas práticas, como já vem ocorrendo com as catadoras de mangaba. Porém, essa valorização econômica pode intensificar a coleta e prejudicar a sustentabilidade da atividade extrativista, sob o aspecto ecológico. Segundo Homma (2012), a sustentabilidade dos recursos extrativistas apresenta mudanças, em decorrência do aumento da procura e, também, em função da adoção de processos tecnológicos.

No que diz respeito a com quem e como aprenderam a coletar, as entrevistadas afirmaram ter aprendido com a mãe $(38,1 \%)$, sozinhas $(23,8 \%)$, com os mais velhos da região $(23,8 \%)$, sendo parentes próximos (avós) ou não, com amigos, vizinhos e família (14,3\%). Tal constatação corrobora com a investigação de Sarmento e Pastore Jr (2006), quando afirmam que o extrativismo se deve ao fato de que os conhecimentos e práticas envolvem a cultura local e são transmitidos de geração para geração, via oral, o que configura uma rede de troca de conhecimento.

Durante a entrevista, também foi questionado o porquê de se coletar o cambuí. A pergunta foi aberta e as entrevistadas puderam responder conforme a percepção de cada uma. Assim, os motivos citados foram baseados em três motivações: $42,85 \%$ das mulheres responderam que coletam o cambuí por gostar do fruto/coletar; 19,04\% coletam devido ao cambuí fazer parte da alimentação; $38,1 \%$ objetivam a renda obtida pela comercialização. Assim, a renda obtida com a comercialização do fruto é um dos fatores que mais estimulam as entrevistadas para a coleta, ressaltando a importância do fruto para cada extrativista, seja ela associada ou não.

\section{Processo de coleta e cuidados de conservação}

No que se refere às estratégias para facilitar o processo de coleta do cambuí, $76 \%$ das extrativistas entrevistadas afirmaram que não existe uma única maneira adotada. O cambuí é coletado de forma manual e depositado em pequenas vasilhas, ou nas próprias roupas (blusas) e depois despejado em baldes:

Abaixando os galhos e catando aqueles mais acessíveis e coloca no balde. Cuidado com a maneira de catar pra não retirar o talo do fruto para evitar murchar ou apodrecer. (Entrevista 01, 47 anos) 
Interessante ressaltar que $24 \%$ das entrevistadas mencionaram que colocam um pano no chão e vão derrubando os frutos para evitar que caiam na areia. Uma (4,75\%) entrevistada desenvolveu uma nova metodologia de coleta: afirmou que utiliza uma garrafa pet cortada e amarrada ao pescoço para deixar a coleta mais ágil.

Sim. Cortei uma garrafa pet e amarrei uma corda de um lado e do outro e coloquei no pescoço pra catar com as duas mãos. (Entrevista 09, 29 anos)

A melhor época para a coleta, segundo as extrativistas, é do início ao meio da frutificação, pois os frutos estão maduros em maior quantidade. O horário de coleta é realizado pela manhã bem cedo, em dias ensolarados. A justificativa, segundo as entrevistadas, é que, pela manhã, a temperatura é mais amena e, no início da tarde, elas já estão retornando. Geralmente, o horário de saída é por volta das 04h:40min. da manhã e o retorno é por volta das 13:00h, em média, 8 horas de trabalho/dia.

Para $71,4 \%$, a duração do crescimento do fruto até a sua maturação varia, em média um mês e meio, o que consideram ser rápida.

Num instante ele bota, num instante ele se acaba. (Entrevista 02, 65 anos)

Um mês e meio. Madurecem rápido, acaba logo. (Entrevista 04, 55 anos)

De acordo com 47,6\% das entrevistadas, a floração ocorre entre os meses de fevereiro e maio, e a frutificação pode ocorrer entre maio e julho, ocorrendo também no mês de agosto, como aconteceu na produção de 2017.

Alguns cuidados para a conservação dos frutos e do cambuizeiro são tomados durante a coleta, tais como: evitar a retirada do "talo" (pedúnculo) do fruto para não danificar e comprometer a qualidade; evitar quebrar os galhos da árvore e retirar os frutos verdes. Diante disso, foi questionado se os galhos quebravam durante a coleta, e $81 \%$ das entrevistadas afirmaram não quebrar os galhos do cambuizeiro, mas $19 \%$ disseram que, às vezes, isso acontece, principalmente quando a árvore é mais alta.

Lima e Scariot (2010), ao pesquisar as práticas de coleta da mangabeira, constataram que a quebra dos galhos pode reduzir a produção nos anos seguintes, além de contribuir para o aparecimento de doenças e insetos que podem causar a morte da planta. Com relação ao cambuí, não é possível afirmar que a quebra dos galhos pode contribuir para a redução da produção, uma vez que não foram 
encontrados trabalhos científicos, tratando do tema. Porém, a quebra de galhos é percebida pelas entrevistadas como um fator negativo para a produção.

Quando eu pego, não. Se eu quebrar, na próxima, não vai botar. (Entrevista 09, 29 anos)

Não. Faço de tudo para eles não quebrar, quebrando vai ter prejuízo, não vai ter no outro ano. (Entrevista 04, 55 anos)

Neste contexto, segundo $85,7 \%$ das entrevistadas, há cuidados que devem ser tomados durante a coleta do cambuí, tais como: não quebrar os galhos; não derrubar os frutos na areia; ter cuidado para não "machucar" os frutos que são sensíveis; não retirar ou derrubar os frutos verdes. Assim, para as entrevistadas, o que se deve fazer é retirar somente os frutos maduros, pois, segundo elas, deve-se deixar os frutos verdes para que outras pessoas possam coletar posteriormente, quando atingirem a maturação, e deve-se preservar os pés (árvores) para que haja frutos novamente, no ano seguinte.

Contudo, de acordo com uma das entrevistadas, nem todas as pessoas têm a preocupação com a conservação das árvores, pois algumas pessoas quebram os galhos para poder levá-los para a sombra para retirar os frutos.

Não pode quebrar os galhos, mas tem gente que quebra pra ir pra sombra. (Entrevista 08,34 anos)

No que se refere a alguma medida de cuidado e/ou manejo com a espécie nas áreas de coleta, $81 \%$ afirmaram não haver, pois são áreas nativas, possuem outros donos ou são livres e são distantes. Existe somente o cuidado na hora da coleta. Sobre as formas de coleta, 85,7\% disseram que não "maltratam" os cambuizeiros e, segundo elas, o que poderia ser feito para a conservação da espécie é evitar e proibir o desmatamento, não quebrar os galhos - porque eles acabam morrendo -, acabar com a seca, limpar as áreas, adubar, cuidar e até mesmo cultivar.

Proibir o desmatamento, se tivesse uma lei que proibisse. (Entrevista 05, 41 anos)

Primeiro deveria ser cercado, segundo ter cuidado pra não quebrar os galhos porque eles terminam morrendo e limpar a área. (Entrevista 03, 53 anos)

Fazer plantio em seus próprios terrenos. (Entrevista 06, 24 anos) 
Quando questionadas se alguma das entrevistadas já produziu uma muda de cambuí na sua propriedade, somente $14,3 \%$ mencionaram ter tentado produzir.

Peneirei o suco e joguei no mato a semente e passou muito tempo, cambuí não gosta de limpeza, tem que tá entrançado. Dei fé deles nascendo quero limpar, mas estou com medo deles morrer; dá muito trabalho. (Entrevista 03, 53 anos)

Sim. Joguei ali na frente da casa e nasceu, só que ainda vou mudar, a gente chupa e sacode os caroços; põe água todo dia. (Entrevista 04, 55 anos)

Quanto às dificuldades na coleta, os fatores mais citados foram: a distância e o "sol quente" (calor); a separação dos frutos verdes dos maduros numa mesma árvore, no momento de coleta, fato comum no início da produção; a separação dos frutos maduros dos frutos murchos no final do período de produção, visto que o processo de separação pode danificar os frutos verdes, pois muitos caem e também os frutos maduros, "amassando-os" no início e no final da safra, respectivamente - isso ocorre devido à sensibilidade do fruto e, principalmente, ao clímax da maturação e início do processo de queda natural.

Segundo as entrevistadas, a quantidade coletada por pé varia em média de meio a três litros, sendo que elas conseguem coletar de 5 a 25 litros por dia. A respeito da quantidade coletada em 2017, considerando-se aproximadamente o envolvimento de 56 extrativistas, segundo a declaração das 21 entrevistadas, estimou-se, em média, 332 litros/safra. Valor semelhante foi coletado pelos extrativistas em Ribeira do Pombal, na Bahia, aproximadamente 301,7 litros, em 2014, com o envolvimento de 70 extrativistas, segundo a declaração de 12 entrevistados (GAMA et al., 2017).

Convém ressaltar que o IBGE (2016b) não apresenta informações sobre a contribuição do estado de Sergipe na produção do cambuí. O referido documento oficial faz referência apenas a dois municípios: Crato (4t.) e Santana do Cariri (4t.), ambos localizados no Ceará. A falta de precisão nas estatísticas oficiais referentes aos PFNM, com base extrativista, é uma crítica já indicada por Gomes et al. (2010), referente à fava-d’anta (Dimorphandra sp), utilizada pela indústria farmacêutica, e a aroeira-da-praia, utilizada pela indústria condimentar (Schinus terebintifolius Raddi).

Quando questionadas se coletam todos os frutos maduros de uma árvore, 71,4\% das entrevistadas afirmaram que sempre acabam deixando alguns frutos nos pés, principalmente quando a área tem boa produção. Sobre a seleção dos frutos, 61,9\% afirmaram que há escolha dos frutos no momento da coleta, pois os frutos maiores enchem os recipientes (baldes/vasilhas) mais rápido e possuem mais polpa. 
A coleta do cambuí é realizada por mulheres que vão em grupos, acompanhadas de familiares, amigas e vizinhas. Porém, cada uma coleta individualmente.

Vai em grupo, mas cada um coleta de forma individual. (Entrevista 08, 34 anos)

Individual, mas vai todo mundo junto. (Entrevista 14, 42 anos)

O número de pessoas da mesma família que coletam os frutos de cambuí variou de 1 a 8 pessoas, ou até mesmo a família inteira, que, nesta pesquisa, somou-se aproximadamente um total de 56 pessoas que se dedicam à atividade extrativista do cambuí, porém nem todos os membros que coletam comercializam os frutos. Por diversas vezes, eles coletam para ajudar algum membro da família ou para seu próprio consumo.

Apesar de ter sido observada certa participação de outros membros da família na coleta, $38,1 \%$ das entrevistadas disseram que não há participação de outros familiares e, destes, 14,3\% não comercializam o fruto.

Basicamente, a busca pelos frutos, quando envolve familiares, pode ocorrer de três formas:

1. A família inteira coleta de forma individual, isto é, cada um coleta os frutos e o valor recebido depende da quantidade coletada por cada um;

Todo mundo cata. E o valor depende da quantidade que cada um pega. (Entrevista 13,26 anos)

2. Vários membros ou a família inteira coletam para ajudar outra pessoa da família, por exemplo, com filhos que ajudam as suas mães;

Sim. A família toda. Eles me ajudam, mas só eu vendo. (Entrevista 19, 48 anos)

3. Vários membros da família, mas somente um comercializa o fruto e os outros coletam para consumo próprio.

Sim. Quatro pessoas coletam para comer. Mas só eu vendo. (Entrevista 17, 50 anos)

Segundo $85,7 \%$ das entrevistadas, a coleta não é realizada todos os dias. Ela pode ser realizada de 2 a 3 vezes na semana, em dias alternados ou de 8 em 8 dias. Os fatores pelos quais a coleta não é realizada todos os dias estão relacionados à: distância, pois, segundo as entrevistadas, 
"acaba sendo cansativo"; quantidade coletada, que pode ser insuficiente e insatisfatória, até mesmo pelo fato de outras pessoas coletarem no mesmo dia ou durante a semana nas mesmas áreas e também no caso de haver muitos frutos verdes, pois deve-se esperar o tempo de maturação.

\section{Locais de coleta e características dos frutos}

Quando questionadas sobre os locais de coleta, foram citadas dez (10) áreas, sendo nove (9) localizadas no povoado Ribuleirinha e uma (1) no povoado Caueira, localizado no município de Itaporanga D’Ajuda.

A coleta do cambuí é feita em "áreas de terceiros ou livre". Apenas uma $(4,75 \%)$ das entrevistadas coleta em sua propriedade. Quanto às "áreas livres", 71\% das entrevistadas assim as consideram pelo fato de "ninguém impedir" e porque "todo mundo coleta". Porém, enfatizaram que “as áreas são livres, mas têm dono". Neste sentido, foi questionada a existência de conflitos nessas áreas, no momento de coleta, e a resposta foi unânime: afirmaram não haver conflitos ou nunca ter presenciado algum incidente.

Em relação à distância para chegar aos locais de coleta, as entrevistadas não souberam responder quantos quilômetros, mas, sim, o tempo gasto para chegar ao local. Em locais mais próximos, gastam de 20 a 30 minutos e, em locais mais distantes, de 1 a 2 horas de caminhada. Para o povoado Caueira, elas se deslocam de carro, deixam o veículo no acostamento da estrada e vão caminhando até a área de coleta, porque, segundo elas, é pasto e área de restinga. Neste caso, o deslocamento pode ser feito com um veículo em, pelo menos, metade do percurso, porém em áreas de mata que são distantes, o percurso geralmente é feito a pé.

Em meio a tantas áreas de coleta, foi questionado se há diferença nas características dos frutos para cada local de ocorrência. As entrevistadas (61,9\%) afirmaram que essa diferença existe, em características relacionadas à cor, ao tamanho e ao sabor. Foi mencionado que, em um local no povoado, predominam os cambuizeiros que produzem frutos de cambuí de coloração amareloalaranjado e os da Caueira são maiores e mais doces.

Diante dessas afirmações, recomenda-se a realização de estudos in loco mais aprofundados, envolvendo a ecologia da espécie, relacionando as diferenças morfológicas com aspectos ambientais regionais e a genética populacional. Uma pesquisa realizada por Silva et al. (2012), no município de Itaporanga D’Ajuda, também localizado no sul do estado de Sergipe, identificou duas cores diferentes para o fruto: 1. de cor amarela [laranja-vermelho] com polpa amarela [amarelo-laranja]; 2. de cor roxa [violeta-azul] com polpa vermelha [vermelho-roxo]. 
Quanto à escolha para cada local de coleta, foi questionado se as entrevistadas conseguiam identificar as árvores de maior produção do fruto e 52,3\% afirmaram que sim, sendo que as localizações variaram de acordo com a opinião de cada uma delas. O tempo de coleta pode influenciar nesse aspecto, pois quem tem mais tempo pode conhecer melhor as áreas e identificar essa produção.

Face ao exposto, foi apontado que as árvores que produzem frutos de "variação amarela" (Figura 1) são maiores, por terem mais galhos, e produzem mais.

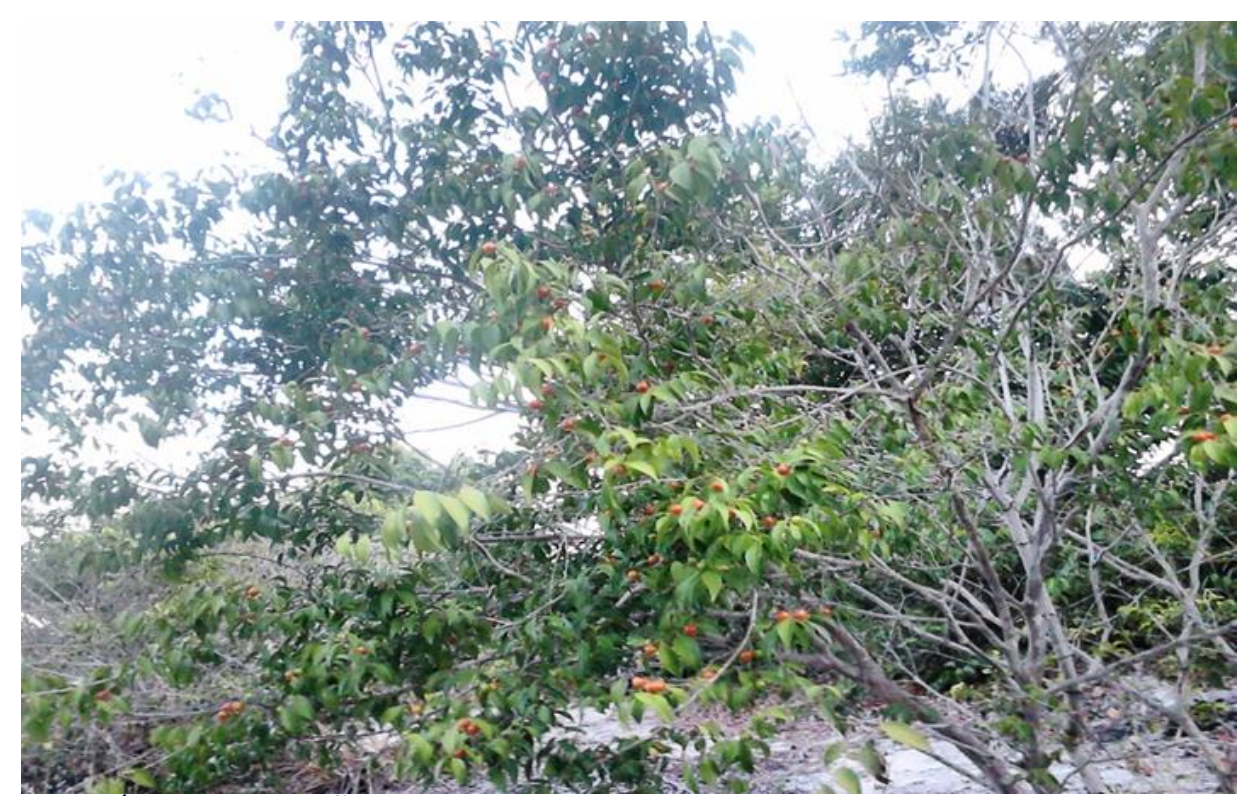

FIGURA 1 - CAMBUÍ DE VARIAÇÃO AMARELO-ALARANJADO. POVOADO RIBULEIRINHA, ESTÂNCIA SERGIPE

FONTE: Liziane Rodrigues dos Santos (2018)

\section{Comercialização e renda}

Com relação ao destino do cambuí, após a coleta, 76,2\% das extrativistas utilizam o fruto tanto para consumo próprio quanto para a comercialização. Somente $23,8 \%$ das entrevistadas utilizam o fruto somente para o consumo próprio. A quantidade deixada para cada destino está relacionada com a quantidade coletada, que, segundo as entrevistadas, em 2017, a quantidade deixada em casa variou de 1 a 10 litros e a quantidade destinada à venda variou de 5 a 20 litros. 
Para consumo próprio, o cambuí é aproveitado principalmente in natura (Figura 2) e na forma de suco e licor, além de outros usos como mousse, sorvete, geleia, biscoito e polpas para suco. Vale destacar que estes mesmos usos foram citados nas pesquisas, com enfoque etnobotânico, realizadas por Fonseca-Kruel e Peixoto (2004), Gama et al. (2017) e Andrade et al. (2016).

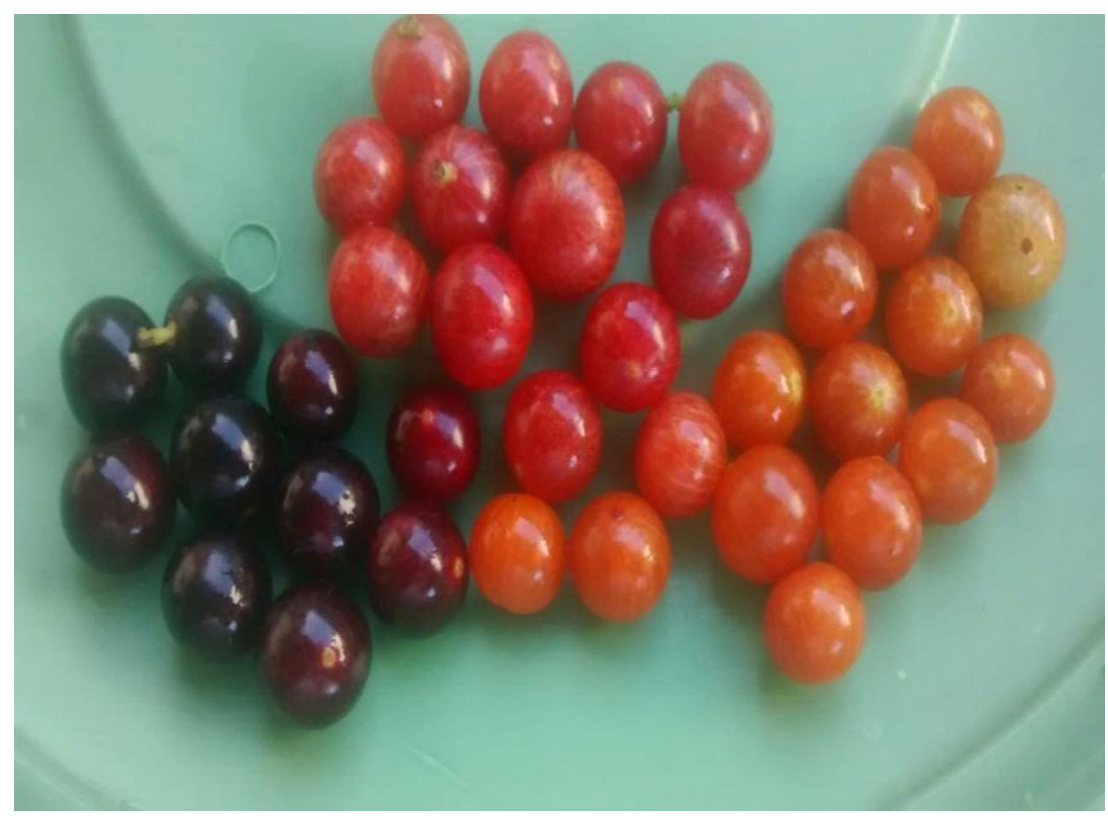

FIGURA 2 - CAMBUÍ IN NATURA E DIFERENTES CORES DOS FRUTOS

FONTE: Liziane Rodrigues dos Santos (2018)

Estudos científicos indicam potencialidades do cambuí para a indústria farmacêutica, a exemplo do estudo realizado por Schneider et al. (2008), que concluiu que o óleo volátil da espécie Myrciaria tenella apresentou bom potencial antimicrobiano, principalmente, frente ao Enterobacter sp., Shigella flexnerii e Enterococcus faecalis.

A medida adotada para saber a quantidade coletada e comercializada é o litro. O preço de venda do litro, em 2017, variou de $\mathrm{R} \$ 4,00 / 1$ a $\mathrm{R} \$ 8,00 / 1$, embora o valor mais comumente aplicado tenha sido de $\mathrm{R} \$ 5,00 / 1$. O valor de $\mathrm{R}$ \$, 00 foi aplicado no início do período de coleta, pois, segundo 
as entrevistadas, a oferta é menor, e $\mathrm{R} \$ 4,00$ do meio para o final, quando a oferta aumenta. Aparentemente, o cambuí parece ter maior valor de mercado na Bahia, de acordo com o que foi registrado por Gama et al. (2017): no final do período de coleta do cambuí, em Ribeira do PombalBA, em 2014, o preço do litro variou entre $\mathrm{R} \$ 10,00$ e $\mathrm{R} \$ 15,00$.

Uma das entrevistadas ainda mencionou que, antigamente (12 anos atrás), o litro do cambuí era vendido em feira livre (Estância) por R\$ 2,50, mas, nos últimos anos, incluindo 2017, chegou a ser vendido por $\mathrm{R} \$ 5,00$, porque as pessoas passaram a gostar do fruto e dos produtos advindos, como sorvete e picolé produzidos por sorveterias locais. Nesse sentido, houve um maior conhecimento sobre o aproveitamento do fruto pelos compradores e, consequentemente, a valorização do fruto no mercado.

O cambuí é vendido em feiras livres nos municípios de Estância e Itaporanga D’Ajuda ou por encomendas realizadas por sorveterias, aos turistas e a pessoas conhecidas. A Associação de Catadoras de Mangaba do Povoado Ribuleirinha (ASCAMARE) tem utilizado o cambuí para a fabricação de produtos como trufa, biscoito, geleia e licor (Figura 3), embora a procura ainda seja pouca na associação, pois, segundo uma das integrantes: "Quem vem de fora não conhece o fruto e fica com receio de comprar" (Entrevista 12, 44 anos). 


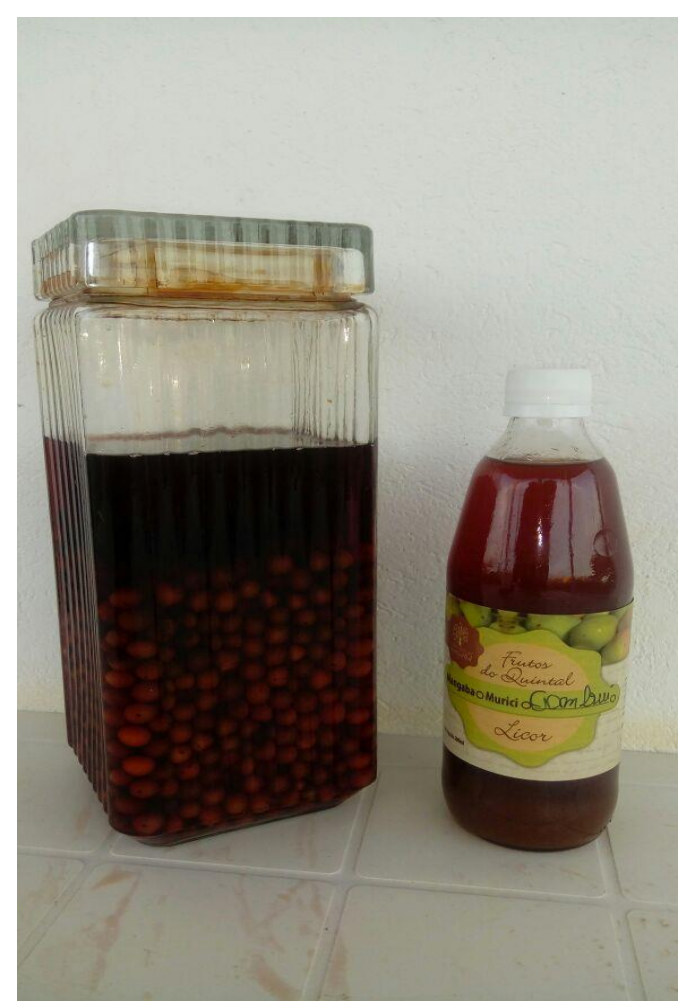

FIGURA 3 - LICOR DE CAMBUÍ PRODUZIDO NA ASSOCIAÇÃO DAS CATADORAS DE MANGABA NO POVOADO RIBULEIRINHA (ASCAMARE), ESTÂNCIA-SE

FONTE: Tainara Nascimento Vidal (ASCAMARE, 2017)

Em 2017, o fruto in natura gerou uma renda estimada entre R \$ 20,00 e R \$ 165,00. Além de ser vendido in natura, ele também é vendido processado, na forma de licor, produzido por duas (02) das entrevistadas, cujo litro varia de $\mathrm{R} \$ 10,00$ a $\mathrm{R} \$ 15,00$. Segundo uma das entrevistadas, que faz parte da ASCAMARE, no ano de 2017, ela conseguiu obter uma renda de R $\$ 225,00$ por vender 15 litros ( $\mathrm{R} \$ 15,00 / 1)$, sendo que com um litro de cambuí ela faz 2 litros de licor e os licores foram produzidos na própria associação.

Pode-se afirmar que o extrativismo do cambuí é tido como uma renda complementar, por ter seu período de produção curto (1 a 2 meses). Neste sentido, durante a entrevista, foi feito um calendário sazonal das atividades de geradoras de renda junto com as entrevistadas, equivalente ao ano de 2017 (Quadro 1), e quando foram questionadas qual delas gera maior renda, o extrativismo da mangaba foi citado por $95 \%$ das entrevistadas. Desta maneira, pode-se afirmar que as mulheres que estão envolvidas com o extrativismo do cambuí são também catadoras de mangaba, independente de participarem da associação de catadoras de mangaba local, ASCAMARE. 
QUADRO 1 - CALENDÁRIO SAZONAL DE ATIVIDADES GERADORAS DE RENDA DAS ENTREVISTADAS EXTRATIVISTAS DO CAMBUÍ. POVOADO RIBULEIRINHA, ESTÂNCIA-SE.

\begin{tabular}{|l|l|l|l|l|l|l|l|l|l|l|l|l|l|l|}
\hline Atividades & JAN & FEV MAR ABR & MAI JUN & JUL & AGO SET OUT NOV DEZ \\
\hline Pesca & & & $\mathrm{x}$ & $\mathrm{x}$ & & & $\mathrm{x}$ & $\mathrm{x}$ & $\mathrm{x}$ & $\mathrm{x}$ & $\mathrm{x}$ & $\mathrm{x}$ \\
\hline Extrativismo do cambuí & & & & & $\mathrm{x}$ & $\mathrm{x}$ & $\mathrm{x}$ & $\mathrm{x}$ & & & & \\
\hline Extrativismo da mangaba & $\mathrm{x}$ & $\mathrm{x}$ & $\mathrm{x}$ & $\mathrm{x}$ & $\mathrm{x}$ & $\mathrm{x}$ & & & & $\mathrm{x}$ & $\mathrm{x}$ & $\mathrm{x}$ \\
\hline Bolsa familia & $\mathrm{x}$ & $\mathrm{x}$ & $\mathrm{x}$ & $\mathrm{x}$ & $\mathrm{x}$ & $\mathrm{x}$ & $\mathrm{x}$ & $\mathrm{x}$ & $\mathrm{x}$ & $\mathrm{x}$ & $\mathrm{x}$ & $\mathrm{x}$ \\
\hline Segura da pesca (defeso) & $\mathrm{x}$ & $\mathrm{x}$ & & & $\mathrm{x}$ & $\mathrm{x}$ & & & & & $\mathrm{x}$ & $\mathrm{x}$ \\
\hline Aposentad oria & $\mathrm{x}$ & $\mathrm{x}$ & $\mathrm{x}$ & $\mathrm{x}$ & $\mathrm{x}$ & $\mathrm{x}$ & $\mathrm{x}$ & $\mathrm{x}$ & $\mathrm{x}$ & $\mathrm{x}$ & $\mathrm{x}$ & $\mathrm{x}$ \\
\hline Outras & $\mathrm{x}$ & $\mathrm{x}$ & $\mathrm{x}$ & $\mathrm{x}$ & $\mathrm{x}$ & $\mathrm{x}$ & $\mathrm{x}$ & $\mathrm{x}$ & $\mathrm{x}$ & $\mathrm{x}$ & $\mathrm{x}$ & $\mathrm{x}$ \\
\hline
\end{tabular}

FONTE: Elaborado a partir de dados obtidos em campo 2017/2018.

O estudo realizado por Jesus et al. (2011) constatou que o extrativismo, mesmo em caráter sazonal, pode ser a principal fonte de renda de comunidades, pois, no caso da aroeira-da-praia (Schinus terebinthifolius Raddi.), o extrativismo sazonal dos frutos foi a principal fonte de renda das famílias em comunidades localizadas às margens do baixo curso do rio São Francisco - Sergipe e Alagoas. Segundo os autores, tal informação é subestimada por órgãos que divulgam dados oficiais, a exemplo do Instituto Brasileiro de Geografia e Estatística (IBGE), o que acaba por não expressar de forma concreta a importância socioeconômica que o extrativismo de PFNM representa para inúmeras comunidades em diversas regiões do Brasil.

\section{Considerações finais}

As extrativistas do cambuí entrevistadas são mulheres oriundas, predominantemente, do município de Estância (81\%) e moradoras do povoado Ribuleirinha (76,2\%). Aliado ao fato de que realizam a coleta desde a infância e adquiriram o conhecimento relacionado ao extrativismo do fruto com parentes próximos, ficou constatado que elas possuem inúmeros conhecimentos e práticas adotados localmente em relação ao extrativismo do cambuí.

Neste sentido, destaca-se o conhecimento do histórico relacionado à atividade extrativista do fruto, que, segundo as entrevistadas, ocorre há cerca de 50 anos e possui duas mudanças significativas nos últimos anos: 1) diminuição do número de indivíduos, diminuição na produção e redução da quantidade coletada, devido à devastação da vegetação, em detrimento a outros usos da terra; 2) aumento da importância dada ao fruto e aos coprodutos, isto é, valorização do produto no mercado consumidor. 
Com relação ao processo de coleta e a cuidados de conservação com a espécie, ficou evidente que o sistema extrativista preponderante na comunidade é dotado de metodologia e tecnologia simples, baseadas nos conhecimentos locais e transmitidas ao longo de gerações. As mulheres extrativistas coletam os frutos, utilizando-se de suas próprias roupas, forram o chão abaixo das árvores ou utilizam adereços simples como garrafas tipo PET. Elas detêm conhecimentos e saberes a respeito da espécie (floração e frutificação), da melhor época para o início da coleta e dos melhores horários para sua realização.

Além disso, demonstraram valorizar e preocupar-se com a conservação da espécie, por meio de cuidados práticos durante a coleta dos frutos, a fim de promover a manutenção das árvores e da produção (cuidado ao coletar para não ocorrer danos aos galhos), bem como a preocupação em cultivar a espécie, como uma alternativa de conservação dela (desejo de que ocorra a proibição do desmatamento, diminuição da seca e realização de manejo nas áreas de ocorrência dos cambuizeiros).

Ainda demonstraram conhecer diferentes locais de coleta e realizaram associações entre locais de coleta e variedades dos frutos (tamanho, coloração) - o que é uma importante informação para pesquisas acerca dos diferentes tipos de cambuí existentes na região. Com relação aos locais de coleta, é importante destacar que apenas uma das entrevistadas possui cambuí em terras próprias - as demais realizam o extrativismo em terras de terceiros ou "livres" e, apesar de não relatarem conflitos, estão à mercê da conservação destas terras, por parte de seus proprietários para manterem a atividade extrativista.

Destaca-se que, apesar de ter sido apontada como uma atividade feminina, outros membros da família também contribuem com a mão de obra na coleta, durante os picos de produção - o que demonstra a importância do fruto para o âmbito familiar. Contudo, para as entrevistadas que, além do consumo familiar, realizam a comercialização dos frutos $(76,2 \%)$, esta atividade é considerada apenas como um complemento para a renda, pois o que elas recebem com a venda da coleta, que é sazonal e curta (apenas 2 meses), não é suficiente para suprir todas as necessidades e gastos domésticos e, por isso, elas exercem outras atividades geradoras de renda.

Apesar da comercialização ser basicamente dos frutos in natura, novas formas de agregação de valor ao produto estão surgindo, dentro e fora da comunidade, a exemplo dos coprodutos (licor, suco, sorvete e picolé). É importante ressaltar que, segundo as entrevistadas, até mesmo o valor do fruto in natura aumentou, nos últimos anos, devido à maior procura por sorvetes e picolés de cambuí em sorveterias no interior do estado, e que, quando beneficiados pelos próprios extrativistas, os 
coprodutos agregam ainda mais valor, contudo ainda são pouco comercializados, pois o fruto não é tão conhecido pelos turistas que visitam a região (em comparação com a mangaba, por exemplo).

Reflete-se, porém, que a procura elevada causa maior exploração. Esse fenômeno, sem um planejamento adequado, pode levar à insustentabilidade do extrativismo de Produtos Florestais Não Madeireiros, como o cambuí. Assim, apesar do extrativismo da mangaba ser atualmente a principal atividade geradora de renda do povoado, a demanda pelos frutos de cambuí tem aumentado, indicando a necessidade de ampliar os conhecimentos em relação ao uso da espécie.

Neste sentido, entende-se que os novos estudos e debates sobre o extrativismo do cambuí, no estado de Sergipe, devem ser realizados por meio do diálogo entre o conhecimento local - derivado do acúmulo de experiências vivenciadas, em busca de meios para a subsistência, em prol do bemestar familiar - e estudos relacionados à ecologia da espécie, produção de mudas para plantio, enriquecimento e manejo das áreas nativas, a fim de traçar estratégias que garantam a manutenção da biodiversidade local a longo prazo.

\section{Referências}

ALBUQUERQUE, U.; HANAZAKI, N. Árvores de valor e o valor das árvores: Pontos de conexão. Recife, PE: Sociedade Brasileira de Etnobiologia e Etnoecologia, 2010.

ALENCAR, E. Introdução à metodologia de pesquisa social. Lavras: Editora UFLA, 1999. 100 p.

ANDRADE, R. S. et al. A restinga como recurso para as comunidades costeiras: o caso da comunidade quilombola Santa Cruz - Brejo Grande, SE. In: 3ํㅗN SEMINÁRIO NACIONAL ESPAÇOS COSTEIROS, 2016, Salvador: UFBA, Campus Ondina, 2016. p. 1-16. Disponível em: https://portalseer.ufba.br/index.php/secosteiros/article/view/18463/11849. Acesso em: 23 maio 2018.

CERQUEIRA, L. Guia do diagnóstico participativo. Rio de Janeiro, 2015. 24p. Disponível em: <http://flacso.org.br/files/2015/08/Guia-do-Diagnostico-Participativo.pdf>. Acesso em: 04 set. 2017.

CORADIN, L.; CAMILLO, J. Introdução. In: BRASIL. Ministério do Meio Ambiente. Secretaria de Biodiversidade. VIEIRA, R. F. (Ed.); CAMILLO, J. (Ed.); CORADIN, L. (Ed.). Espécies nativas da flora brasileira de valor econômico atual ou potencial: Plantas para o Futuro: Região Centro-Oeste / Ministério do Meio Ambiente. Brasília, DF: MMA, 2016. Disponível em: http://agriculturaconsciente.com.br/wp-content/uploads/2017/08/Plantas-para-oFuturo_Regi\%C3\%A3o-Centro-Oeste.pdf. Acesso em: 03 dez. 2017.

FIGUEIREDO, L. D. Empates nos babaçuais: do espaço doméstico ao espaço público - lutas de quebradeiras de coco babaçu no Maranhão. 2005. Dissertação (Mestrado em Agriculturas Familiares e Desenvolvimento Sustentável) - Centro Agropecuário, Núcleo de Estudos Integrados sobre 
Agricultura Familiar, Empresa Brasileira de Pesquisa Agropecuária, Universidade federal do Pará, Belém.

FONSECA-KRUEL, V. S.; PEIXOTO, A. L. Etnobotânica na Reserva Extrativista Marinha de Arraial do Cabo, RJ, Brasil. Acta Botanica Brasilica, São Paulo, v. 18, n. 1, p. 177-190, jan./mar. 2004. Disponível em: http://www.scielo.br/scielo.php?script=sci_arttext\&pid=S010233062004000100015. Acesso em: 03 dez. 2017.

GAMA, D. C. et al. O cambuí (Myrciaria tenella (DC.) O. Berg; Myrtaceae): extrativismo e geração de renda em Ribeira do Pombal-Bahia. Revista Brasileira de Agroecologia, [S.1.], v. 12, n. 1, p. 4251, mar. 2017. Disponível em: <http://revistas.abaagroecologia.org.br/index.php/rbagroecologia/article/view/20753>. Acesso em: 03 dez. 2017.

GOMES, L. J.; GOMES, M. A. O. Extrativismo e biodiversidade: o caso da fava-d'anta. Ciência Hoje, vol. 27, n. 161, p. 66-69, jan. 2000. Disponível em: https://www.researchgate.net/publication/288467135_O_extrativismo_e_biodiversidade_O_caso_d a_fava-d\%27anta. Acesso em: 03 dez. 2017.

GOMES, L. J. et al. (Org.). Pensando a biodiversidade: aroeira (Schinus terebinthifolius Raddi). São Cristóvão: Editora UFS, 2013. 372 p.

GOMES, L.J.; GOMES, M. A. O.; JESUS. N. B. de. Aspectos socioambientais da atividade extrativista de produtos florestais não madeireiros: os casos da Fava-D'Anta (Dimorphandra sp) e da Aroeira-da-praia (Schinus terebinthifolius Raddi). In: ALBUQUERQUE, U. P.; HANAZAKI, N. (Org.). Árvores de valor e o valor das árvores: pontos de conexão. v. 1. Recife: NUPEEA, 2010. p. 65-107.

HOMMA, A. K. O. Extrativismo vegetal ou plantio: qual a opção para a Amazônia? Estudos Avançados, São Paulo, v. 26, n. 74, p. 167-186. 2012. Disponível em: <https://www.revistas.usp.br/eav/article/view/10631.doi:http://dx.doi.org/10.1590/S010340142012000100012>. Acesso em: 03. fev. 2018.

IBGE. Instituto Brasileiro de Geografia e Estatística. Densidade demográfica do município de Estância. IBGE, 2016a. Disponível em: <http://www.cidades.ibge.gov.br/xtras/perfil.php?lang=\&codmun=280210>. Acesso em: 02 jul. 2017.

IBGE. Instituto Brasileiro de Geografia e Estatística. Produção da Extração Vegetal e Silvicultura. v. 31. Rio de Janeiro: IBGE, 2016b. 55p. Disponível em: https://www.ibge.gov.br/estatisticasnovoportal/economicas/agricultura-e-pecuaria/9105-producao-da-extracao-vegetal-e-dasilvicultura.html?=\&t=downloads. Acesso em: 15 jul. 2018.

JESUS. N. B. de; SANTANA, L. L.; GOMES, L. J. Extrativismo: reflexões para a gestão florestal da aroeira (Schinus terebInthifolius Raddi) no Baixo São Francisco - SE-AL. In: AGUIAR NETTO, A. F.; LUCAS. A. A. T. (Org.). Águas do São Francisco. v. 1. São Cristóvão: Universidade Federal de Sergipe, 2011. p. 291-308. 
LIMA, B. F. Vida e trabalho: um estudo sobre as mulheres extrativistas de mangaba na Ilha do Marajó, Estado do Pará. 2012. Dissertação (Mestrado em Agriculturas Familiares e Desenvolvimento Sustentável) - Universidade Federal do Pará, Belém.

LIMA, I. L. P.; SCARIOT, A. Boas práticas de manejo para o extrativismo sustentável da Mangaba. Brasília: Embrapa Recursos Genéticos e Biotecnologia, 2010. 68 p.

MENEZES, S. F. S. et al. Diagnóstico Rural Participativo (DRP) uma ferramenta necessária para investigação/intervenção: experiência do projeto Cajusol no território do Seridó (RN). Área Temática: Desenvolvimento e Espaço: ações, escalas e recursos. In: I CIRCUITO DE DEBATES ACADÊMICOS, 2011, [S.1.]: Instituto de Pesquisa Econômica Aplicada (Ipea), 2011, 13p. Disponível em: http://www.ipea.gov.br/code2011/chamada2011/pdf/area7/area7-artigo59.pdf. Acesso em: 20 jul. 2018.

MORAIS, L. M. F.; CONCEIÇÃO, G. M.; NASCIMENTO, J. M. Família Myrtaceae: Análise Morfológica e Distribuição Geográfica de uma Coleção Botânica. Agrarian Academy, Centro Científico Conhecer, Goiânia, v. 1, n. 01, p. 317, 2014. Disponível em: http://www.conhecer.org.br/Agrarian\%20Academy/2014a/familia.pdf. Acesso em: 03 dez. 2017.

MOTA, D. M. da et al. O extrativismo de mangaba é "trabalho de mulher"? Duas situações empíricas no Nordeste e Norte do Brasil. Novos Cadernos NAEA, [S.1.], v. 11, n. 2, p. 155-168, dez. 2008. Disponível em: <http://www.periodicos.ufpa.br/index. php/ncn/article/view/276/423>. Acesso em: 31 jan. 2018.

OLIVEIRA, D. M. de et al. Coletânea bibliográfica acadêmica sobre a mangabeira (Hancornia speciosa Gomes). Gaia Scientia, [S.1.], v. 11, p. 212-231, 2017a.

OLIVEIRA, D. M. de et al. Identificação dos pontos críticos no sistema extrativista da mangaba (Hancornia speciosa Gomes) em Sergipe. Guaju, Matinhos, v.3, n.1, p. 11-36, jan./jun. 2017b.

OLIVEIRA, W. L.; SCARIOT, A. Boas práticas de manejo para o extrativismo sustentável do pequi. Brasília: Embrapa Recursos Genéticos e Biotecnologia, 2010. 84 p.

PEREIRA, F. A. et al. Análise da atividade extrativista do pequi (Caryocar coriaceum Wittm) em comunidades da chapada do Araripe na região do cariri cearense. Conexões Ciência e Tecnologia, [S.1.], v.8, $\quad$ p. 59-66, 2014. <http://conexoes.ifce.edu.br/index.php/conexoes/article/view/693/470>. Acesso em: 30 jan. 2018.

PROENÇA, C. E. B.; LANDIM, M. F. L.; OLIVEIRA, M. I. U. In: PRATA, A. P. N. et al. (Org.). Flora de Sergipe: Myrtaceae. 1 ed. v. 1. Aracaju: Gráfica e Editora Triunfo, 2013. p. 202-202.

RODRIGUES, R. F. de A. et al. Mapa do extrativismo da mangaba em Sergipe: situação atual e perspectivas. Brasília, DF: Embrapa, 2017. 55 p.

SANTOS, M. A. dos. Análise Geoambiental do município costeiro de Estância-Sergipe. 2011. Dissertação (Mestrado em Geografia) - Núcleo de Pós-graduação em geografia, Universidade Federal de Sergipe, São Cristóvão. 
SARMENTO, R. T.; PASTORE Jr, F. Projeto ITTO PD 31/99 Rev.3 (I) Produção não-madeireira e desenvolvimento Sustentável na Amazônia Objetivo Específico No. 1, Resultado 1.3 Diagnóstico do extrativismo em eixos de análise. Brasília: Universidade de Brasília, 2006. 79p. Disponível em: http://www.itto.int/files/itto_project_db_input/2202/Technical/1.3\%20Diagn\%C3\%B3stico\%20do $\% 20$ extrativismo\%20em\%20eixos\%20de\%20an\%C3\%A1lise.pdf. Acesso em: 27 out. 2017.

SCHNEIDER, F. Z. et al. Estudo dos compostos voláteis e atividade antimicrobiana da Myrciaria tenella (cambuí). Revista Brasileira de Farmacologia, [S.1.], v. 89, n. 2, p. 131-133, 2008.

SILVA, A. V. C. et al. Fruit and seed biometry of cambuí (Myciaria tenella O. Berg). Revista Agroambiente On-line, v. 6, n. 3, p. 258-262, 2012. Disponível em: https://revista.ufrr.br/agroambiente/article/view/831. Acesso em: 27 out. 2017.

SILVA, E. G. Implicações da atividade extrativista sobre a estrutura populacional, densidade e viabilidade do banco de sementes de Syagrus coronata (Mart.). Beccari. 2010. Dissertação (Mestrado em Ecologia e Biomonitoramento) - Instituto de Biologia, Universidade Federal da Bahia, Salvador. Disponível em: <http://www.repositorio.ufba.br:8080/ri/bitstream/ri/12698/1/Disserta\%C3\%A7\%C3\%A3o\%20E.\% 20Guirra.pdf>. Acesso em: 31 jan. 2018.

SILVA, M. G. et al. Potencial de Mandevilla clandestina J. F. Morales (Cipó-de-leite) no artesanato de Parnaíba PI, Brasil. Revista Espacios, v. 37, n. 36, p. 15, 2016.

SILVA, R. R. V. da; GOMES, L. J.; ALBUQUERQUE, U. P. Methods and Techniques for Research on the Supply Chains of Biodiversity Products. In: ALBUQUERQUE, U. P. (Org.) (Ed.). Methods and Techniques in Ethnobiology and Ethnoecology. v. 1. New York: Humana Press, 2014. p. 335348.

SOLDATI, G. T. Produtos florestais não madeireiros: padrões de uso e conservação de Anadenathera colubrina (Vell.) Brenan no Agreste pernambucano. 2009. Dissertação (Mestrado em botânica) - Universidade Federal de Pernambuco, Recife.

TUAN, Y.-F. Topofilia: um estudo da percepção, atitudes e valores do Meio Ambiente. Londrina: Eduel, 2012. 342p.

VINUTO, J. A amostragem em bola de neve na pesquisa qualitativa: um debate em aberto. Temáticas, Campinas, v. 22, n. 44, p. 203-220, ago./dez. 2014.

Artigo recebido em 31/07/2018. Aceito para publicação em 26/10/2018. 